waren die genetischen Korrelationen bei Gewicht hoch ( $\mathrm{r}$ oder wenig darunter), während sie bei Körpermassen im allgemeinen kleiner waren.

Die genetischen Korrelationen waren bei Schlachteigenschaften in fünf von zehn Fällen kleiner als 0,5 . Diese betrafen vor allem die chemische Zusammensetzung der Muskeln.

\title{
MILCHLEISTUNG VON VIER RASSEN BEI VERSCHIEDENEM FUTTERNIVEAU
}

F. Pirchner. - Tievärztliche Hochschule, Wien (Österreich).

Es wurden je ro bis 24 Kalbinnen der vier österreichischen Hauptrassen Fleckvieh, Braunvieh, Pinzgauer und Murbodner auf drei verschiedene Futtergruppen aufgeteilt. In der schwach gefütterten Gruppe wurde täglich I $\mathrm{kg}$ Kraftfutter, in der mittleren $3 \mathrm{~kg}$ und in der stark gefütterten täglich $5 \mathrm{~kg}$ Kraftfutter zusaätzlich zu Rauhfutter und Silage ohne Rücksicht auf Milchleistung gegeben. Der Fütterungsversuch begann 30 Tage postpartum und verlief über I6 Wochen. Der Futterverzehr wurde für jede Kuh bestimmt.

Die Stärkewertaufnahme hat in den drei Futtergruppen in dem Versuchszeitraum von I6 Wochen 553, 7 Io und $805 \mathrm{~kg}$ betragen. Milchleistung, FCM Ertrag, Proteingehalt und Gewichtszunahme zeigten signifikante Futtergruppeneinflüsse und, mit Ausnahme der Gewichtszunahme, auch signifikante Rasseneinflüsse. Fettgehalt der Milch zeigte zwar Unterschiede, die ähnlich der bei Proteingehalt waren, doch erreichten sie in bezug auf Futtereinflüsse nicht statistische Signifikanz.

Durchschnittsleistungen in 16 Versuchswochen

\begin{tabular}{|c|c|c|c|c|c|c|c|}
\hline & \multicolumn{4}{|c|}{ Rassen } & \multicolumn{3}{|c|}{ Futtergruppen } \\
\hline & $F l$ & $B r$ & $P i$ & $M u$ & 1 & 2 & 3 \\
\hline Milch-kg . . . . . . & 1067 & 1153 & 877 & 776 & 871 & 987 & 1047 \\
\hline $\mathrm{FCM} \ldots \ldots \ldots$ & 1018 & 1055 & 840 & $75^{\prime} \mathbf{x}$ & 814 & 945 & 992 \\
\hline Protein- $\% \ldots \ldots$ & 3.21 & 3.22 & 3.47 & 3.62 & 3.27 & 3.34 & $3.5^{\prime}$ \\
\hline Zuwachs-kg ..... & 38 & 33 & 51 & 37 & 21 & 39 & 60 \\
\hline
\end{tabular}

Trotz erheblicher Unterschiede im Fütterungsniveau und deutlicher Rassenunterschiede ware keine statistisch signifikante Interaktionen zu beobachten.

\section{Divers}

\section{AI BREEDING STRATEGY FOR DUAL-PURPOSE CATULLE POPULATIONS}

A. E. McClintock and E. P. Cunningham. - Animal Breeding and Genetics Dept., An Foras Taluntais, Dublin (Eire).

The first prerequisite in any problem of animal selection is a meaningful definition of the breeding objective. This presents special difficulties in the case of dual-purpose AI bulls, because the bull's beef and dairy genotypes will be exploited to different extents. A method 